\title{
ANALYSIS OF THE CURRENT SITUATION WITH THE PROCESS OF DEINSTITUTIONALISATION IN THE REPUBLIC OF MACEDONIA WITH A FOCUS ON 10 TARGET MUNICIPALITIES
}

\begin{abstract}
The social protection system of the Republic of Macedonia consists of centers, institutions, measures, activities, and norms realized within the exercise of rights and services' provision to citizens in the area of social protection. The system is upgraded through the expertise of the institutes for social protection (which carry out development programs and work on the professional specialization of workers depending on the needs of beneficiaries and international standards), situation monitoring and work planning, keeping records as well as the implementation of supervision and research in this area.

The process of Deinstitutionalization of people with disabilities will be impossible without a strong network of service providers, the private sector from that region because both of them are relevant stakeholders to develop models of education, employment, social and health services to facilitate independent living of people with disability.

Through this approach, tailored models, addressing the needs of the targeted individuals in one institution, as representatives of people with disabilities, have been developed in all ten municipalities and should be included in national policies. More specifically, by adapting protocols, guidelines, training modules to ensure accessibility and acceptability of services for people with disabilities in the above 10 mentioned municipalities, barriers to existing services will be removed and the attainment of the highest possible level of services for people with disabilities will be sought1.
\end{abstract}

Keywords: DEINSTITUTIONALISATION, PEOPLE WITH DISABILITIES, SOCIAL PROTECTION SYSTEM

\section{Introduction}

Results from the process of Deinstitutionalization of people with disabilities till now:

\footnotetext{
${ }^{1}$ The research is conducted within the project Supporting Modernization and De-Institutionalisation of the Social Services implemented by European Union Delegation to the R. of North Macedonia
} 
- Children and adults with disabilities benefit from an improved system of support that enables them to leave closed residential institutions and pursue independent lives in the community;

- Community-based services are developed and individual employment plans prepared to assist adults from the Banja Bansko in reintegrating into society;

- Training is necessary to education staff in Skopje, Kumanovo, Veles, Stip, Demir Kapija, Kavadarci, Strumica, Tetovo, Ohrid, Bitola to enable them to design and provide inclusive education programs for children with disabilities;

- A professional community of practice on inclusive education is established;

- Training tools are developed and training is delivered to foster families to improve the care provided to children with disabilities;

- The capacity of persons with disabilities to advocate for their rights is increased and persons with disabilities find greater acceptance in their local communities;

- Awareness-raising initiatives, including training manuals, on understanding their rights and mapping of opportunities for alternative (non-institutional) care for better inclusion in the society are implemented; - Support mechanisms are designed for biological and foster families to better respond to the different needs of male and female children with disabilities while ensuring a focus on social inclusion;

- Good practices for social inclusion and integrated support including access to non-discriminatory, gender-responsive health and social protection services, inclusive education, and inclusive labor market are documented;

- Support is provided to caregivers in biological and foster families to improve the quality of care for children and adults with disabilities.

Another successful program is the Self-employment Programme which is an essential part of the country's employment strategy and the national active labor market measures which have been designed to promote smart, sustainable, and socially inclusive growth.

The main objective of this project is to reduce unemployment by encouraging the creation of small businesses that will provide a living for successful entrepreneurs. Furthermore, the Programme has a community works component that tackles social exclusion on two fronts at once, offering unemployed people a chance to gain valuable working experience and improve their professional skills while providing services for those who are most at risk of social exclusion.

The specific activities primary targets several groups of beneficiaries: pre-school children, elderly people, adults, and children with disabilities as well as citizens of rural areas who are entitled to receive health and/or educational services. To date, 198 persons with disabilities have completed the en- 
trepreneurship training while 146 businesses have been registered. 32,19\% are women with disabilities entrepreneurs who opened their own businesses.

Training

Organize info sessions and training with NGOs from all cities to motivate new service providers in the field of non-family care. Currently, there are only three providers covering personal assistance.

- Organize training for service management. There are many CSOs on the territory of the country, but a small number deal with social protection services.

- Organize training for personal planning in all social protection institutions.

- Organize training for CSWs for integrated work.

- Organize training for carers to deal with people with severe intellectual disabilities and motor disorders.

The drafting partner for preparing personal planning may be the Faculty of Philosophy from Ss. Cyril and Methodius University in Skopje has signed a cooperation agreement with the Ministry of Labour and Social Policy. Students from the institutes for special education and rehabilitation, social work and social policy, and psychology can work together across the country. At each institute, one professor will mentor the work, and each student will be tasked with submitting quarterly and annual reports.

For the employees of the centers for social work, the biggest burden is the "case management" task, which this year is the responsibility of the professionals introduced for the first time and represents extra time and effort. The introduction of this task is considered to be the most noticeable problem with the insufficient number of employees in the social work centers. The capacities of the CSW staff are limited. They further point to the need for thorough and practical training in the application of this method of work. It is necessary to introduce "tailor-made" services for the user.

\section{NEEDS ANALYSIS IN THE CITIES TARGETED FOR THIS RESEARCH}

- All cities have needed to develop or increase daycare centers, social clubs, foster families, small group homes, units for support, personal assistants, and centers for early intervention;

- Although the deinstitutionalization process is not new and a series of activities and campaigns have already been carried out, there is still a need for ongoing information campaigns to change public awareness. All point to the need to increase the number of employees in the CSW and to increase and equip all day center profiles as a guarantee of successful implementation of work responsibilities. All point out that people living in rural areas are not treated equally 
because of lack of community services, but also organized transportation for those who could use them in urban areas;

- The cities targeted by this research have several foster families and small group homes, but when it comes to people with disabilities the numbers are reduced or none at all;

- The City Red Cross of Skopje employs 23 licensed personal assistants who serve 31 users.

The priorities of the cities in the following period are:

Bitola

- Opening a day-care center for adults with disabilities, over $18 / 26$ years, who are currently visiting the day-care center where the age limit is up to $18 / 26$ years, so there are no vacancies for younger people who need this service;

- Opening a day-care center for early interventions of children with disabilities, up to the age of six, where individual rehabilitation will be offered to improve the condition of the youngest;

- Opening a day-care center or temporary accommodation for children at risk because of the large number of children in need of this service;

- Provide personal assistants for sign language interpreters to assist deaf people across institutions;

- Providing interventional foster families;

- Providing an additional number of foster families for the purpose of fostering people in their municipality.

\section{Veles}

- Personal assistance to the elderly and persons with disabilities. So far, over 130 applications for personal assistants for people with cerebral palsy, blind people, people with physical disabilities and the elderly have been received;

- Providing foster families in the municipality so that persons in need of foster care are not sent to families in other municipalities;

- Opening small group homes in the municipality so that people in need do not move into small group homes or large institutions in other municipalities. 


\section{Demir Kapija}

- Encouraging families in the municipality to take care of children, as there are currently no foster families;

- Opening a day-care centre for people with disabilities, since there are no such centers in either Demir Kapija or Negotino;

- Development of an idea for utilization of the empty capacities of the Special Institution - one of the needs for housing of the elderly can be realized by converting the office into an elderly home.

Kavadarci

- Opening a day-care centre for people with severe disabilities over 18 years of age, since there is currently a day-care centre for minors;

- Providing interventional foster families in the municipality, which are currently missing, so that those in need are cared for while providing other forms of social support;

- Opening small group homes in the municipality so that people in need do not move into small group homes or large institutions in other municipalities.

\section{Kumanovo}

- Opening a day-care center for rehabilitation of persons with cerebral palsy, where they will receive appropriate intervention and support.

\section{Ohrid}

- Opening a Day-care center for children with severe disabilities, aged 6-18, who due to the severity of the disability are not able, at present to access regular education due to the lack of capacity of the education system;

- Providing foster families in the municipality so that persons in need of foster care are not sent to families in other municipalities;

- Opening small group homes in the municipality so that people in need do not move into small group homes or large institutions in other municipalities. 


\section{Skopje plan region}

\section{Aerodrom}

- Developing appropriate support and support services, but also the inclusion of children aged seven to eighteen, who for some reasons may not be included in the educational process through the inclusion process;

- Raising public awareness, counseling, assistance, and support on how people with disabilities can be included in the community, education, labor market for the general population and for people with disabilities, as well as parents about the importance of the independence process of these persons;

- Informing the general public, people at risk, but also the business sector about the importance of social entrepreneurship and developing it as an opportunity to integrate people into the labor market and to overcome the risk of unemployment and material insecurity.

\section{Butel}

- Develop early intervention prevention programs and services for children with disabilities from 0 to 7 years, which will include professional treatment, counseling, and professional work with both parents of children and other children in the family. These programs and services would be part of the integration and inclusion processes of both children and families;

- Development of service centers for children with disabilities and their families, especially at the age of 15 - 26 years (which could be used as a resource center by the PI Institute for Rehabilitation of Children and Youth). It would also be supportive of personal assistants and other service providers of this population. These centers would be part of the integration and inclusion processes of both children and families;

- Ensuring the sustainability of group living with the support of residential units for people with intellectual disability over 26 years, by opening another "My Home 3" residential unit in Drachevo, by being part of the reintegration, in a way that the current dormitory users, to be housed in the area, and to work with them on their independence so that they will learn how to grow fruits, vegetables, keep pets and provide them with milk, meat, eggs, i.e. products both for food and for sale. They will be hired there, will work, and will benefit from the overall sustainability of housing units and reduce the cost of expensive housing units. 


\section{Gazi Baba}

- Reopening of the Day-Care Centre for Children with Disabilities, providing human and material resources and long-term sustainability.

\section{Gjorche Petrov}

- Opening of the CSW Skopje regional office in the local community Dame Gruev, to be designed for the people in the municipality who are at social risk, and which will be a place where the residents can be informed, offered information service, referral free legal help, where they can address their problems and needs;

- Introduce expert support and psychosocial support services for families with family members in the Sue Ryder Hospice, to assist and support families in overcoming this difficult life situation.

\section{Ilinden} Ilinden.

There is no need to introduce new social services in the municipality of

\section{Karposh}

- Developing appropriate support and support services, but also the inclusion of children aged seven to eighteen, who for some reasons may not be included in the educational process through the inclusion process;

- Opening a day-care center for children with disabilities, whose services will provide help and support to children and parents as service in the community;

- Expand the range of public service providers in the field of social protection, with greater involvement of the civil sector, which is flexible and inexpensive and could emerge as a solid provider of services but funded by the state.

\section{Kisela Voda}

There is no need to introduce new social services related to persons with disabilities in the municipality of Kisela Voda. 
Saraj

- Development of the service of educational assistants, as 60 children with disabilities are registered in the municipality who are probably involved in regular education with the process of inclusive education.

\section{Centar}

- Establishment of service of expert and legal assistance and support to the citizens of the Municipality of Centar within the Municipality of Centar, for the realization of their rights, support for overcoming the problems and risks to which they are exposed.

\section{Chair}

- Developing and implementing information and referral activities for the residents of the municipality on the new forms of home and community service they can obtain, what are their benefits;

- Opening and developing home and community services for people with disabilities and their families to provide appropriate support to meet the needs of these people, as well as to provide support and respite in the care of the parents of these children/persons;

- Providing a budget and sustainability of the educational assistance service for children with disabilities, which is of great need in the municipality of Chair and thus ensuring proper inclusion and integration of children in the community and in the education system.

\section{Shuto Orizari}

In the municipality of Shuto Orizari there is no need to introduce new social services related to persons with disabilities.

\section{Strumica}

The municipality of Strumica is leading by its inclusiveness. The municipality has self-supporting housing units for persons with motor disorders deinstitutionalized by the Banja Bansko Institute. However, the municipality needs to introduce new social services:

- Providing foster families in the municipality so that persons in need of foster care are not sent to families in other municipalities; 
- Opening small group homes in the municipality so that people in need do not move into small group homes or large institutions in other municipalities.

\section{Tetovo}

- Providing foster families in the municipality so that persons in need of foster care are not sent to families in other municipalities;

- Opening small group homes in the municipality so that people in need do not move into small group homes or large institutions in other municipalities.

\section{Shtip}

- Opening a Day-care center for persons with physical disabilities, which will provide rehabilitation, physiotherapy, and sports-recreational activities;

- Providing foster families in the municipality so that persons in need of foster care are not sent to families in other municipalities.

\section{SUMMARY}

From the abovementioned sets of research findings, common threads emerge. Some effort has been made across the region to harmonize legislation with the relevant international human rights framework, including the Convention on the Rights of the Child and the Convention on the Rights of Persons with Disabilities. Nevertheless, more work needs to be done to concentrate and align legal provisions on the specific needs of people with disabilities in all spheres of life, outline the best mechanisms to implement legislation.

Major challenges are identified in putting policy into practice.

Problems highlighted include the limited capacity of key staff, poor coordination between government departments and state and local level authorities, as well as a chronic shortfall in budgets.

Reliable data is a huge concern. Many people with disabilities are thought to be missing entirely from public registers. None of the governments has a definitive number of people living with disabilities. Most have an inconsistent approach to gathering statistics and use neither a universal definition of disability nor a standardized methodology to assess it in line with the Convention on the Rights of Persons with Disabilities.

In a region with a long history of segregating people with disabilities in institutions, efforts are continuing to end institutionalization. However, alternative support services in the community - like day centers and specialist support - are patchy, making it difficult for children to exercise their right to live with 
their families. Non-governmental organizations or disabled people's organizations frequently fill gaps in government provision. Nonetheless, unpredictable funding means these services can downsize or stop at any point. Collaboration between these organizations, working with families on a local level or changing policy, is beginning to build momentum in some places.

Programs to identify children with disabilities at a young age and provide early intervention are either inconsistent or non-existent. The lack of speedy and appropriate response has long-term implications for children's development. When children with disabilities come to be assessed, a medical model is often relied upon, perpetuating the idea that they have problems that need to be detected by health professionals and to be addressed to ICF International Classification of Functionality process which is underway supported both by MOES and MOLSP rather than addressing how each child can be supported to overcome barriers in society that limit them. Inclusive education is being championed; however, this does not always mean children with disabilities are fully participating in learning in classes and in school life, on an equal basis with other children.

Healthcare is unreliable, with many parents feeling forced to resort to expensive private options, often because they do not trust the quality of local practitioners or because waiting lists are too long. Families shoulder the burden of high costs of care, with many parents pushed into poverty. Accessibility is a regularly cited issue.

Public spaces, schools, health facilities, and transport frequently cannot be easily used by people with disabilities and are most often not accessible User-friendly formats like sign language and Braille are seldom employed. Children with disabilities are at increased risk of violence and abuse, although they are often not given any special legal or practical protection.

Discrimination against people with disabilities remains pervasive. Those who are from traditionally marginalized groups like Roma usually face the greatest stigma. This prevents their voices from being heard on issues of importance to them and limits their full participation in all areas of life.

The report concludes that, although barriers exist in some municipalities that keep them from moving completely to a community-based service delivery system, municipalities can use a number of strategies and proposals to eliminate their reliance on institutional care.

These strategies include:

- Building community resource networks and community crisis/ emergency response systems to address the reason people initially are institutionalized;

- Creating systems of long-term care for people with disabilities that are more consumer-driven and include more home-and community-based services;

- Emphasizing the search for better ways to treat disabled individuals both medically and socially; 
- Experimenting with various payment models for personal assistance services, such as direct payment for services and vouchers;

- Convening a task force of legislators, state agencies, providers, and people with developmental disabilities and their families to discuss and report on the service needs of people with developmental disabilities;

- Establishing a state-wide data-collection system that identifies people with developmental disabilities, their demographic and personal characteristics, and their service needs;

- Appropriating money to operate both the institutional and community services until a community-based infrastructure can be developed. 


\section{REFERENCE LIST}

National Deinstitutionalisation Strategy of the Republic of Macedonia for 20182027 'Timjanik' \& Action plan. (2018) Skopje: The Republic of Macedonia Ministry of Labour and Social Policy.

Petreski, M., Tumanoska, D. Social services in the municipalities of North Macedonia: capacity, risks, needs. (2020) Skopje: Finance Think Economic Research and Policy Institute.

Flaker, V., Krstovski, V. Potentials for development of community-based services in the transition from institutional care Technical assistance support for the deinstitutionalisation process in social sector. (2017) A project implemented by the A.E.S.A. Consortium in partnership with Alternative Consulting

Velichkovski, Robert and Chichevalieva, Snezhana. 2010. Children with Disabilities in the Republic of Macedonia. Analysis. Skopje: SouthEastern Europe Health Network.

European Commission. 2012 c. FYR Macedonia 2012 Progress Report. SWD (2012) 332 final. Retrieved from http://ec.europa.eu/enlargement/pdf/ key_documents/2012/package/mk_rapport_2012_en.pdf

European Commission. 2013 c. The former Yugoslav Republic of Macedonia 2013 Progress Report. Retrieved from http://ec.europa.eu/enlargement/ pdf/key_documents/2013/package/brochures/the_former_yugos lav_ republic_of_macedonia_2013.pdf

IDSCS (2017) Social protection and inclusion at local level: Volume of monitoring reports. Skopje: Institute for Democracy Societas Civilis.

Ludwig Boltzmann Institute of Human Rights (2010) Analysis of the state of social protection and social inclusion at local level. Skopje: Ludwig Boltzmann Institute of Human Rights.

Josifovska, B. and Petreski, M. (2018) Analysis of the provision of social services at the local level: Results from the monitoring of the Municipalities of Prilep and Dolneni. Policy study no. 23, Skopje: Economic Research and Policy Institute Finance Think.

PI Institute for Social Activities (2017) Overview of social protection services in the Republic of Macedonia: Overview by regions. Skopje: PI Institute for Social Activities

MoLSP (2013) Handbook on development of social services for the vulnerable groups in the local communities. Skopje: Ministry of Labour and Social Policy. 